
\title{
25 Research Suare \\ Inflammatory Myofibroblastic Tumor of the Sigmoid Colon in an Infant: A Case Report
}

\section{luyao wu}

Tongji Hospital of Tongji Medical College of Huazhong University of Science and Technology

xinyao meng

Tongji Hospital of Tongji Medical College of Huazhong University of Science and Technology

xiaoyi sun

Tongji Hospital of Tongji Medical College of Huazhong University of Science and Technology tianqi zhu

Tongji Hospital of Tongji Medical College of Huazhong University of Science and Technology donghai yu

Tongji Hospital of Tongji Medical College of Huazhong University of Science and Technology jiexiong feng ( $\nabla$ jiexiongfeng@126.com )

Tongji Hospital of Tongji Medical College of Huazhong University of Science and Technology

\section{Case report}

Keywords: case reportðdiagnosis, inflammatory myofibroblastic tumor, pathology, sigmoid colon

Posted Date: August 12th, 2021

DOl: https://doi.org/10.21203/rs.3.rs-775620/v1

License: (c) (i) This work is licensed under a Creative Commons Attribution 4.0 International License. Read Full License 


\section{Abstract}

Background: Inflammatory myofibroblastic tumor (IMT), an infrequent mesenchymal lesion composed of myofibroblastic and fibroblastic spindle cells with inflammatory infiltration, mostly occurred in pediatric patients. IMT has been reported in a number of locations throughout the body. However, the cases occurred in the gastrointestinal tract, especially those involving the sigmoid colon in pediatric patients, are very rare and even have not been reported. Here we present a case of a large IMT originating from the sigmoid colon and invading the omentum and the surrounding tissues in an 11-month-old boy.

Case presentation: The patient is an 11-month-old boy initially presenting with symptoms of fever and vomiting. Abdominal ultrasound revealed an inhomogeneous echo with a size of $9.9 * 4.6 \mathrm{~cm}$ in the left lower abdomen. Abdomen computed tomography (CT) scanning confirmed that a mass with a size of $10 * 8 * 6 \mathrm{~cm}$ located in the left middle and lower abdomen. Post-operative pathological examination confirmed the histopathologic diagnosis of IMT. Complete resection of the tumor along with the involved colon segments were performed and followed by end-to-end colon anastomosis. The boy recovered well without postoperative complications or recurrence during one-year follow-up.

Conclusions: Colon IMT is extremely rare; its etiology and pathogeny are unclear. Imaging examination may provide reliable evidence for determining IMT. However, postoperative histopathologic examination is also important for the final diagnosis. Complete tumor excision, accompanied by rare recurrence and satisfying survival, is the best therapeutic approach at present. This case report may complete the clinical presentation of IMT by reminding physicians not to ignore the possibility of IMT in the colon.

\section{Introduction}

Inflammatory myofibroblastic tumor (IMT) is a rare disorder characterized by the presence of myofibroblasts and inflammatory cells in fibrous stroma(1). Originally described by Umiker and Iverson, IMT generally represents a benign inflammatory process, while malignant phenotypes may emerge and even transform into malignant tumor(2). The lung, mesentery and omentum are considered as the most commonly occurring sites for IMT(3). Notably, it is difficult to distinguish IMT from other neoplasms by radiographic evidence, hence histologic examination is necessary for the definitive diagnosis of IMT(4). Since the management of IMT is not well defined, the challenges remain. The following case described in this paper was a rare kind of IMT occurring in the sigmoid colon and invading the greater omentum.

\section{Case Report}

An 11-month-old boy having a body weight of about 10.3 kilogram $(\mathrm{kg})$ manifested symptoms of fever (with a maximum of $39.8^{\circ} \mathrm{C}$ ) and vomiting (2-3 times per day) for unknown reasons 10 days before admitted to our hospital. Initially, the boy was taken into a local hospital and managed with alexipyretic and antibiotic therapies. After two days of treatment, his symptoms were improved with the body temperature returning to normal. However, a mass was discovered in the left side of the boy's abdomen 
by routine abdominal examination. Abdominal ultrasonography revealed an inhomogeneous echo with $9.9 * 4.6 \mathrm{~cm}$ in size in the left lower abdomen (Fig. 1). Abdomen computed tomography (CT) scanning was then conducted and confirmed that a mass with $10 * 8 * 6 \mathrm{~cm}$ in size was located in the left middle and lower abdomen (Fig. 2).

Testing for tumor biological markers was also performed (Table 1). Only the serum level of neuron specific enolase (NSE) was detected to be slightly elevated $(38.83 \mathrm{ng} / \mathrm{ml})$, while the levels of CA125, AFP, CEA and S100 in the serum were all within their normal ranges. Meanwhile, the tested levels of VMA and HVA in the urine also presented negative results.

Table 1

Laboratory Examination of tumor biological markers.

\begin{tabular}{|c|c|c|}
\hline & results & normal range \\
\hline CA125 & $143.40 \mathrm{U} / \mathrm{ml}$ & $<35 \mathrm{kU} / \mathrm{L}$ \\
\hline NSE & $37.72 \mathrm{ug} / \mathrm{l}$ & $<16.30 \mathrm{ug} / \mathrm{l}$ \\
\hline HVA & $8.31 \mathrm{umol} / 24 \mathrm{~h}$ & $0 \sim 41.86 \mathrm{umol} / 24 \mathrm{~h}$ \\
\hline VMA & $5.2 \mathrm{umol} / 24 \mathrm{~h}$ & $0 \sim 41.28 \mathrm{umol} / 24 \mathrm{~h}$ \\
\hline AFP & $4.68 \mathrm{ng} / \mathrm{ml}$ & $\leq 7 \mathrm{ng} / \mathrm{ml}$ \\
\hline CEA & $0.79 \mathrm{ng} / \mathrm{ml}$ & $\leq 5.0 \mathrm{ng} / \mathrm{ml}$ \\
\hline S100 & $0.063 \mathrm{ug} / \mathrm{l}$ & $<0.105 \mathrm{ug} / \mathrm{l}$ \\
\hline \multicolumn{3}{|c|}{ CA125: Carcinoembryonic Antigen 125} \\
\hline \multicolumn{3}{|c|}{ NSE: Neuron Specific Endase } \\
\hline \multicolumn{3}{|c|}{ HVA: Homovanillicacid } \\
\hline \multicolumn{3}{|c|}{ VMA: Vanilmandelic Acid } \\
\hline \multicolumn{3}{|c|}{ AFP: Alpha Fetal Protein } \\
\hline \multicolumn{3}{|c|}{ CEA: Carcinoembryonic Antigen } \\
\hline
\end{tabular}

Gastroenteric history was not significant, moreover, medical and surgical histories were unremarkable as well. Other laboratory parameters were within normal levels. However, the parameters of $12.73^{\star} 10^{\wedge} 9 / \mathrm{L}$, $103 \mathrm{~g} / \mathrm{L}, 1203 * 10^{\wedge} 9,33.7 \%, 76.8 \mathrm{fl}, 23.5 \mathrm{pg}, 306 \mathrm{~g} / \mathrm{L}$ respectively for white blood cell count, hemoglobin, platelet count, hematocrit, mean corpuscular volume, mean corpuscular hemoglobin, and mean hemoglobin concentration, indicated a hypochromic anemia.

We therefore performed open surgery after controlling the fever and emesis. After careful dissection, exploratory laparotomy revealed a huge solid tumor, with a measurement about $12 * 8 * 4 \mathrm{~cm}$ in the left side 
of the abdominal cavity (Fig. 3). The anterior margin of the tumor was adhesive to the greater omentum, while the upper margin was adhesive to tissues surrounding the small intestine. In addition, another smaller tumor, about $2 * 2 * 2 \mathrm{~cm}$ in size, was found to be located in the omentum. After careful exploration by blunt dissection along the tumor margin, it turned out that the tumor was originated from the wall of sigmoid colon. Finally, the whole tumor together with its invaded colon segments (the resection margin of the colon is about $2.5 \mathrm{~cm}$ to the tumor) were resected and followed by end-to-end colon anastomosis. The whole greater omentum together with other surrounding tissues that the tumor has invaded, were also completely removed. The boy recovered well from the operation, furthermore, no recurrence was detected within one year of follow-up.

Histopathology examination revealed that the tumor was composed of spindle-shaped cells admixed with plasma cells, lymphocytes, neutrophils, eosinophils, and extensive necrotic cells (Fig. 4). Immunohistochemistry revealed positive staining for smooth muscle actin, desmin, and anaplastic lymphoma kinase (ALK-1), while negative for myogenin, CD34, CD117, sox-10 and S-100 protein (Fig. 4). Furthermore, the staining for markers of dendritic cell neoplasms, including CD21, CD23 and CD35, presented negative, while a positive rate for $\mathrm{Ki}-67$ was about $8 \%$. Collectively, the pathologic results robustly confirmed the diagnosis of IMT.

\section{Discussion}

Firstly described in 1937, IMT is composed of proliferating spindle cells and accompanied with a surrounding fibroinflammatory process that typically occurs in children or young adults(5). This benign tumor has been reported to occur mostly in the lung. Nevertheless, multiple extrapulmonary cases have also been reported, the locations of the lesions of extrapulmonary IMT involve the upper respiratory tract, mesentery/omentum, urogenital tract, gastrointestinal tract, mediastinum, retroperitoneum, trunk, pancreas, liver and other areas(6). To our knowledge, there is few literatures reporting pediatric IMT originating from sigmoid colon.

The majority of IMTs are found incidentally in the chest or abdomen, with $15-30 \%$ patients presenting systemic symptoms such as pain, fever, weight loss and anemia $(6,7)$. Laboratory tests may reveal microcytic anemia, a raised erythrocyte sedimentation rate, thrombocytosis, and/or polyclonal hypergammaglobulinaemia(8). In some patients, the tumors may be found after an unknown-cause fever or growth failure(9). The systemic signs generally disappear or relieve after surgical excision, while the appearance of clinical and laboratory abnormalities is a warning sign for tumor recurrence $(6,9)$.

The etiologic factors responsible for the development and tumorigenesis of IMT are not clearly identified. Some researchers think that IMT development occurs after trauma, surgery or infection especially Epstein-Barr virus or human herpes virus, which are related with reactive cytokine production(10). Consequently, the presence of a true neoplasm in view of some investigators is considered as an immunologic response to infectious or noninfectious sources(11). Therefore, future efforts are required to classify this issue. 
The diagnosis of IMT is difficult even at the microscopic level, thus immunohistochemical examinations are necessary to diagnose and differentiate IMT from other diseases, such as gastrointestinal stromal tumors, and inflammatory malignant fibrous histiocytomas $(12,13)$. Spindle-shaped cells with chronic inflammatory cells infiltration are considered as the characteristics of IMT(6). However, immunohistochemistry analysis, rather than radical, is important for definitive diagnosis of an IMT. The IMT cells are usually positive for desmin, vimentin, and smooth muscle actin (SMA), and frequently positive for ALK protein(4). The expression of ALK protein is a good diagnostic marker, while it is only present in about $50 \%$ of the patients with $\operatorname{IMT}(14,15)$. Furthermore, the ALK-positive can also be seen in other types of carcinoma, such as rhabdomyosarcoma, and neuroblastoma(16). Therefore, the results of tumor cells collectively positive for SMA, ALK and desmin, negative for S100, sox10, CD117 and CD34, allow for the final diagnosis of IMT.

Nowadays, the total resection of the mass remains the essential therapy for the treatment of IMT. Besides surgery, a few cases have reported the curing by antibiotics, hormones or non-steroidal anti-inflammatory drugs(17-19). Recently, ALK directed therapy, as an alternative neo-adjuvant therapy, has been developed when the standard surgical treatment is not feasible. Furthermore, partial therapeutic effect on IMT has been described in previous studies(20-22). Nevertheless, the resistance to ALK inhibitor crizotinib appeared about 6 months after the initiation of the treatment when the patients had IMT with ALK rearrangement(20). With the further development of ALK inhibitors, the problem of crizotinib resistance can be solved, thus, the ALK inhibitors hold the promise to be a critical treatment to IMT.

\section{Conclusion}

In conclusion, we reported an extremely rare case of pediatric IMT occurring in an 11-month-old male with IMT invading the sigmoid colon involving the omentum and tissue surrounding the small intestine. According to the case and treatment, it is important to completely remove the tumor since the tumor is large and the efficacy of other treatments is currently unclear.

\section{Abbreviations}

IMT, inflammatory myofibroblastic tumor; ALK, anaplastic lymphoma kinase; CT, computed tomography; MRI, magnetic resonance imaging; SMA, smooth muscle actin.

\section{Declarations}

\section{Ethical approval and consent to participate}

Not applicable, as it is a case report.

\section{Consent for publication}


Informed written consent was obtained from the patient's mother for publication of this case report and accompanying images.

\section{Availability of data and materials}

Not applicable.

\section{Conflicts of interest}

The authors declare that they have no competing interests.

\section{Funding statement}

This study was supported by the National Natural Science Foundation of China (81873541) and the Sanming Project of Medicine in Shenzhen (SZSM201812055).

\section{Authorship}

Investigation and Resources: SXY and ZTQ.

Resources: MXY and WLY.

Writing - original draft: MXY and WLY.

Writing - review \& editing: FJX and YDH.

Funding acquisition: FJX.

All authors read and approved the final manuscript.

\section{Acknowledgements}

We thank the patient and his family for their contribution.

\section{References}

1. Dalton BG, Thomas PG, Sharp NE, Manalang MA, Fisher JE, Moir CR, et al. Inflammatory myofibroblastic tumors in children. J Pediatr Surg. 2016;51(4):541-4.

2. UMIKER WO. IVERSON L. Postinflammatory tumors of the lung; report of four cases simulating xanthoma, fibroma, or plasma cell tumor. J Thorac Surg. 1954;28(1):55-63.

3. Kim EY, Lee IK, Lee YS, Yang N, Chung DJ, Yim KI, et al. Inflammatory myofibroblastic tumor in colon. J Korean Surg Soc. 2012;82(1):45-9.

4. Coffin CM, Hornick JL, Fletcher CD. Inflammatory myofibroblastic tumor: comparison of clinicopathologic, histologic, and immunohistochemical features including ALK expression in atypical and aggressive cases. Am J Surg Pathol. 2007;31(4):509-20. 
5. Lewis PM. Inflammatory Pseudotumor of the Orbit: Report of a Case. Trans Am Ophthalmol Soc. 1937;35:328-35.

6. Coffin CM, Watterson J, Priest JR, Dehner LP. Extrapulmonary inflammatory myofibroblastic tumor (inflammatory pseudotumor). A clinicopathologic and immunohistochemical study of 84 cases. Am J Surg Pathol. 1995;19(8):859-72.

7. Pettinato G, Manivel JC, De Rosa N, Dehner LP. Inflammatory myofibroblastic tumor (plasma cell granuloma). Clinicopathologic study of 20 cases with immunohistochemical and ultrastructural observations. Am J Clin Pathol. 1990;94(5):538-46.

8. Meis JM, Enzinger FM. Inflammatory fibrosarcoma of the mesentery and retroperitoneum. A tumor closely simulating inflammatory pseudotumor. Am J Surg Pathol. 1991;15(12):1146-56.

9. Souid AK, Ziemba MC, Dubansky AS, Mazur M, Oliphant M, Thomas FD, et al. Inflammatory myofibroblastic tumor in children. Cancer. 1993;72(6):2042-8.

10. Karnak I, Senocak ME, Ciftci AO, Caglar M, Bingol-Kologlu M, Tanyel FC, et al. Inflammatory myofibroblastic tumor in children: diagnosis and treatment. J Pediatr Surg. 2001;36(6):908-12.

11. Kovach SJ, Fischer AC, Katzman PJ, Salloum RM, Ettinghausen SE, Madeb R, et al. Inflammatory myofibroblastic tumors. J Surg Oncol. 2006;94(5):385-91.

12. Hirota S. Differential diagnosis of gastrointestinal stromal tumor by histopathology and immunohistochemistry. Transl Gastroenterol Hepatol. 2018;3:27.

13. Carlos O, Rui C, Amelia E, Filipe CA. Retroperitoneal inflammatory myofibroblastic tumor: A case report. Eur J Radiol Open. 2017;4:9-12.

14. Mohammad N, Haimes JD, Mishkin S, Kudlow BA, Leong MY, Chew SH, et al. ALK Is a Specific Diagnostic Marker for Inflammatory Myofibroblastic Tumor of the Uterus. Am J Surg Pathol. 2018;42(10):1353-9.

15. Shukla PS, Mittal K. Inflammatory Myofibroblastic Tumor in Female Genital Tract. Arch Pathol Lab Med. 2019;143(1):122-9.

16. Mossé YP. Anaplastic Lymphoma Kinase as a Cancer Target in Pediatric Malignancies. Clin Cancer Res. 2016;22(3):546-52.

17. Tsou YK, Lin CJ, Liu NJ, Lin CC, Lin CH, Lin SM. Inflammatory pseudotumor of the liver: report of eight cases, including three unusual cases, and a literature review. J Gastroenterol Hepatol. 2007;22(12):2143-7.

18. Koea JB, Broadhurst GW, Rodgers MS, McCall JL. Inflammatory pseudotumor of the liver: demographics, diagnosis, and the case for nonoperative management. J Am Coll Surg. 2003;196(2):226-35.

19. Su W, Ko A, O'Connell T, Applebaum H. Treatment of pseudotumors with nonsteroidal antiinflammatory drugs. J Pediatr Surg. 2000;35(11):1635-7.

20. Butrynski JE, D'Adamo DR, Hornick JL, Dal Cin P, Antonescu CR, Jhanwar SC, et al. Crizotinib in ALKrearranged inflammatory myofibroblastic tumor. N Engl J Med. 2010;363(18):1727-33. 
21. Brivio $E$, Zwaan CM. ALK inhibition in two emblematic cases of pediatric inflammatory myofibroblastic tumor: Efficacy and side effects. Pediatr Blood Cancer. 2019;66(5):e27645.

22. Sandoval L, Franca MV, Sanmartino D, Zattar PF. ALK Negative Inflammatory Myofibroblastic Tumor Synchronous with Classical Hodgkin Lymphoma. Case Rep Oncol. 2019;12(1):119-25.

\section{Figures}

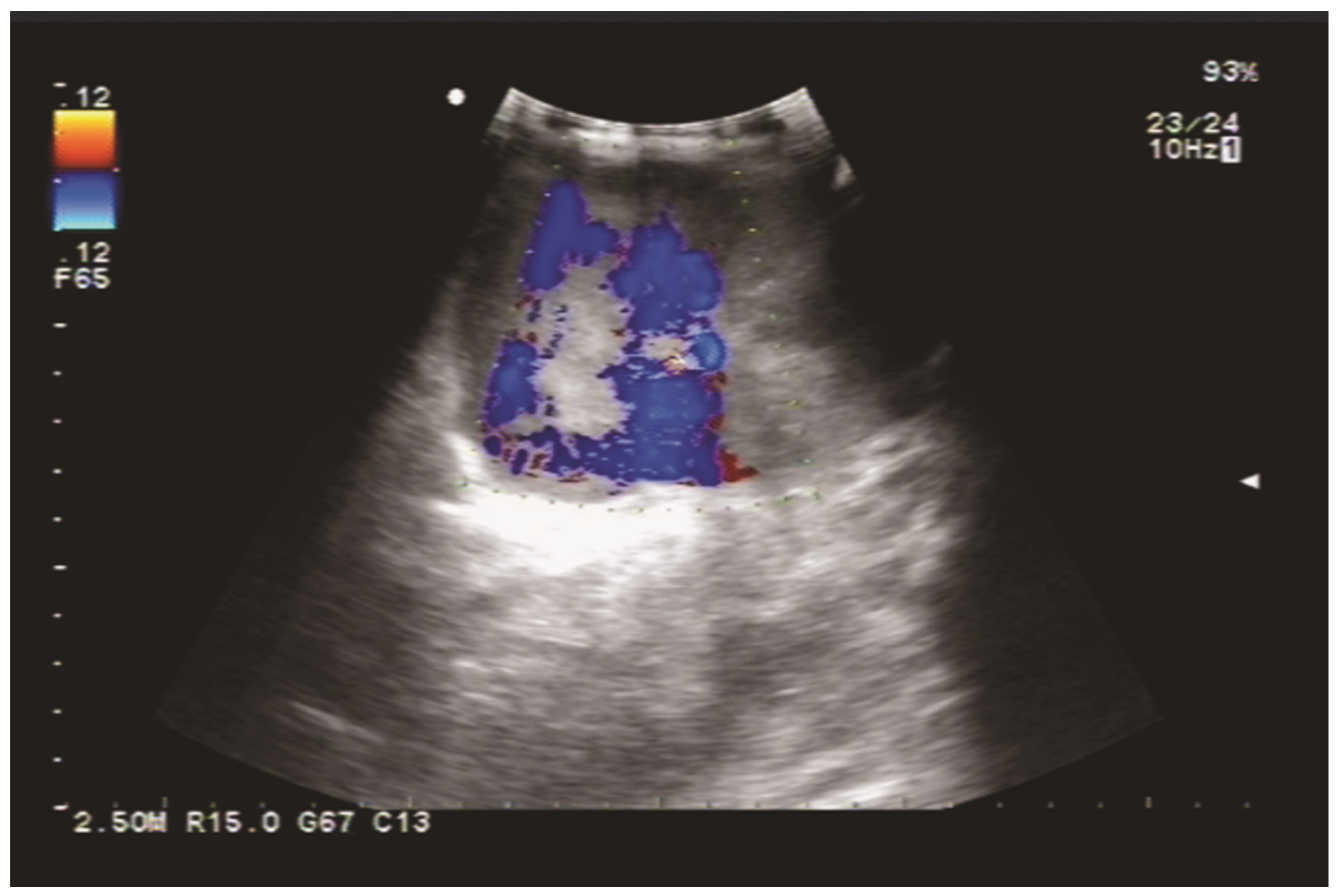

\section{Figure 1}

Ultrasound detection of the abdomen. 


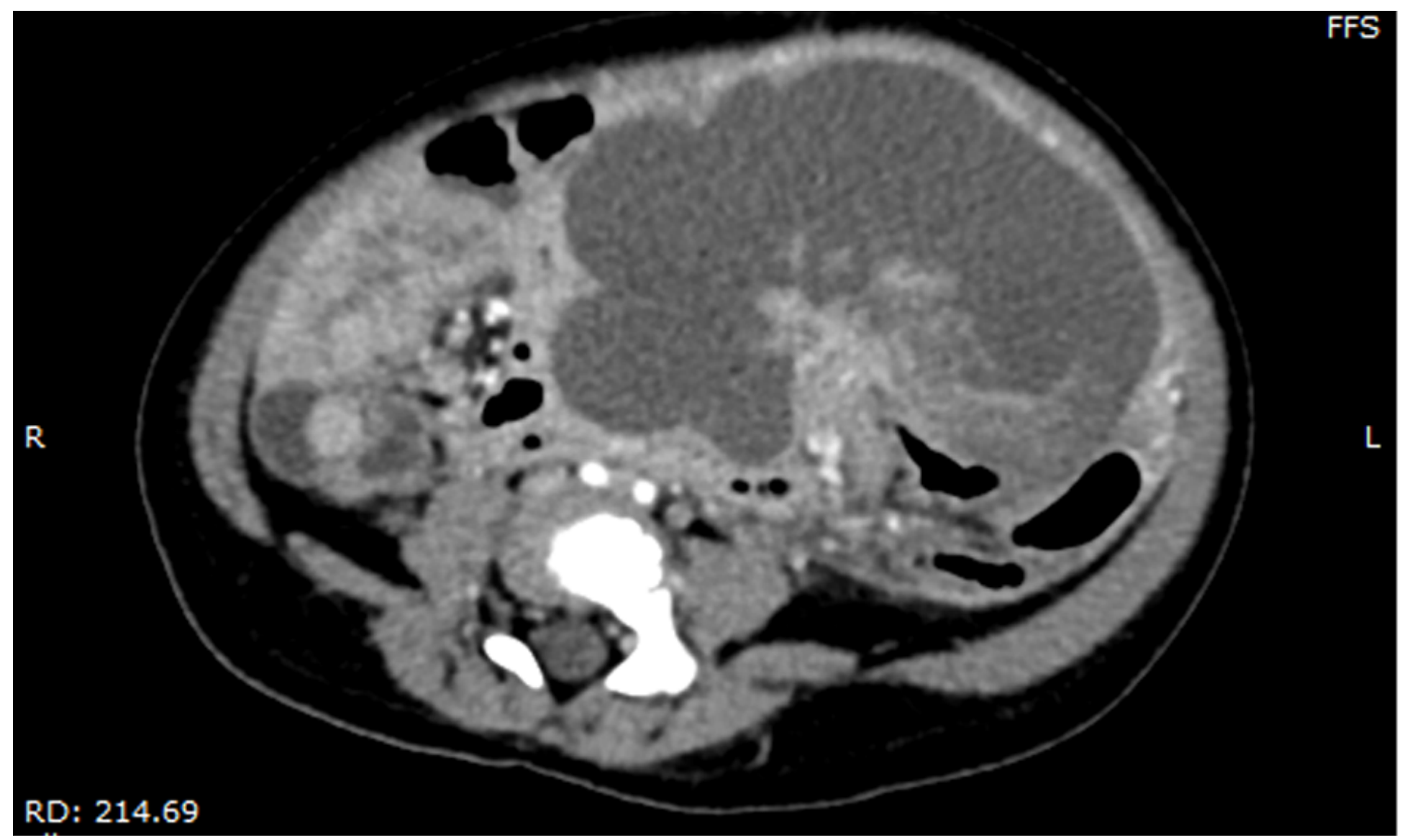

Figure 2

CT scan of the abdomen. 


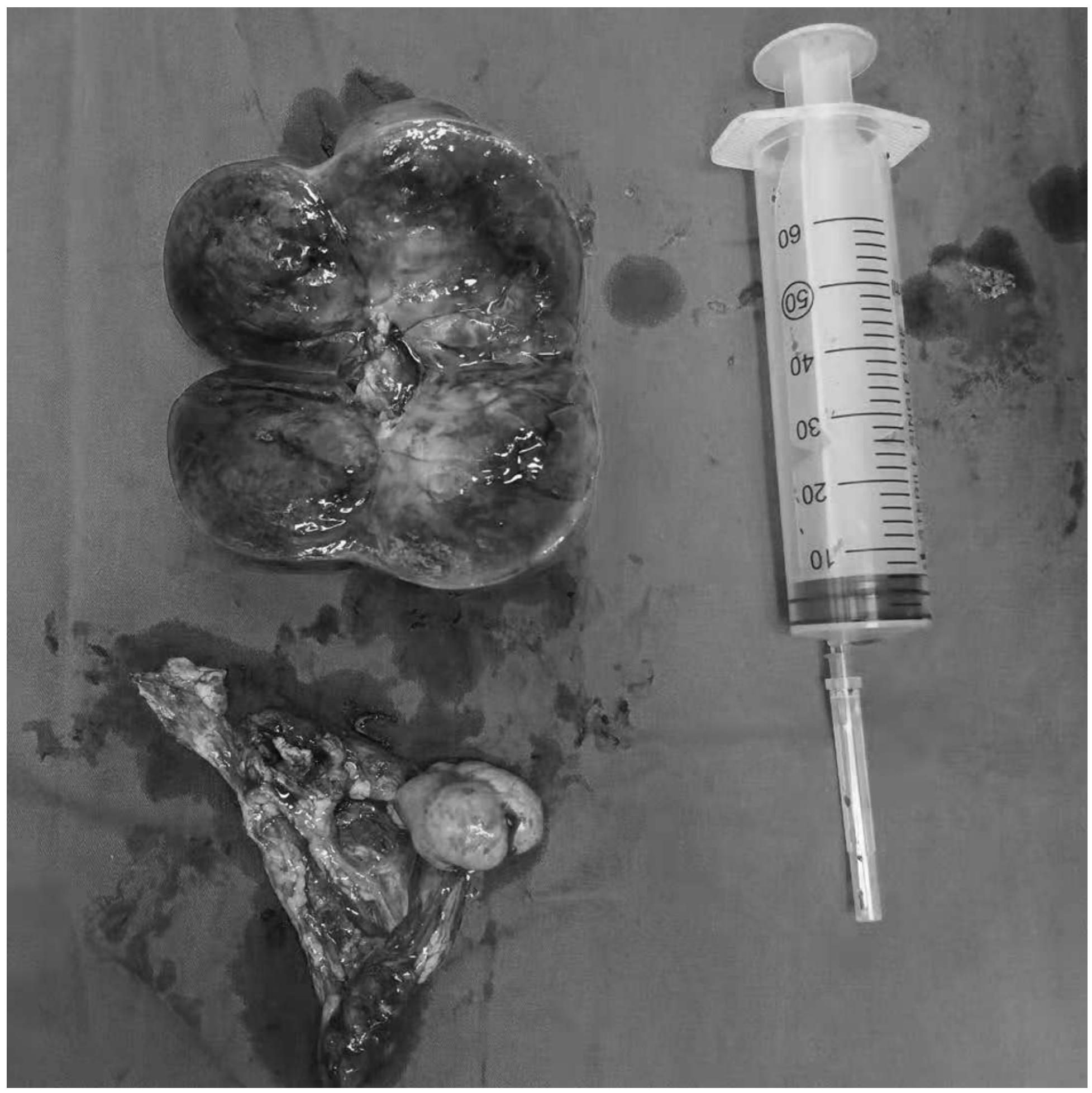

\section{Figure 3}

Intraoperative vision of the tumor, originate from sigmoid colon. 

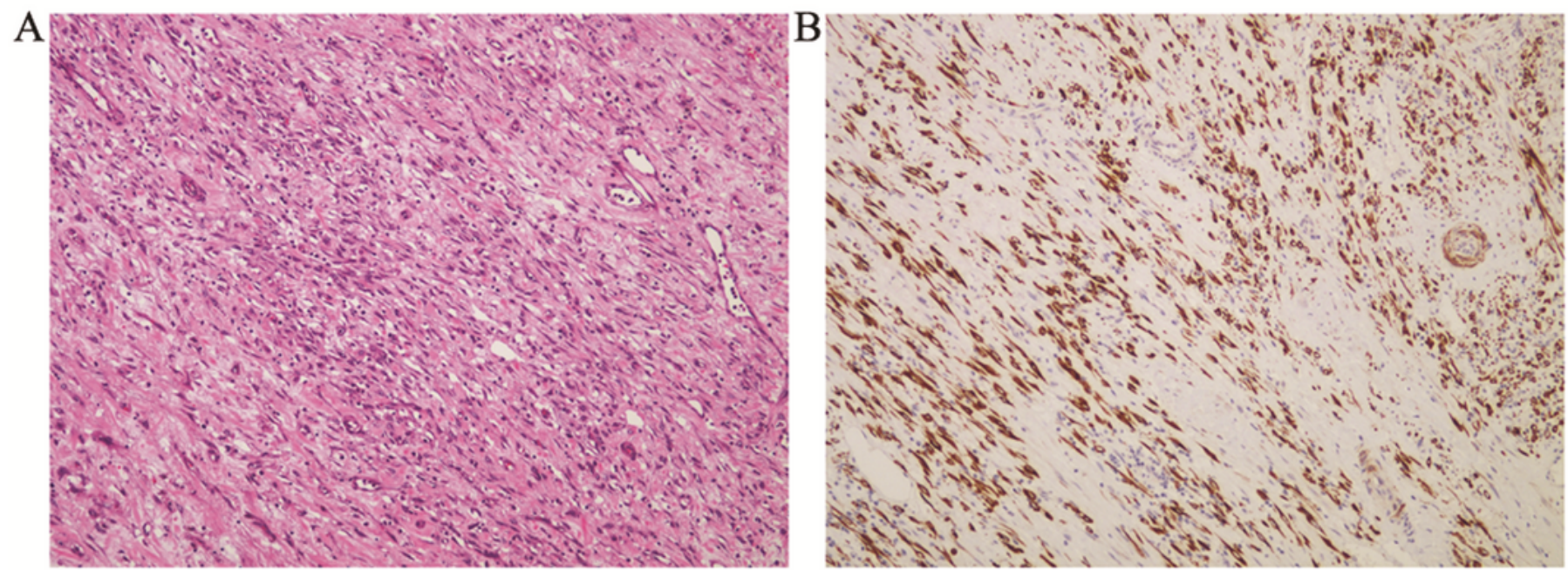

$\mathrm{C}$
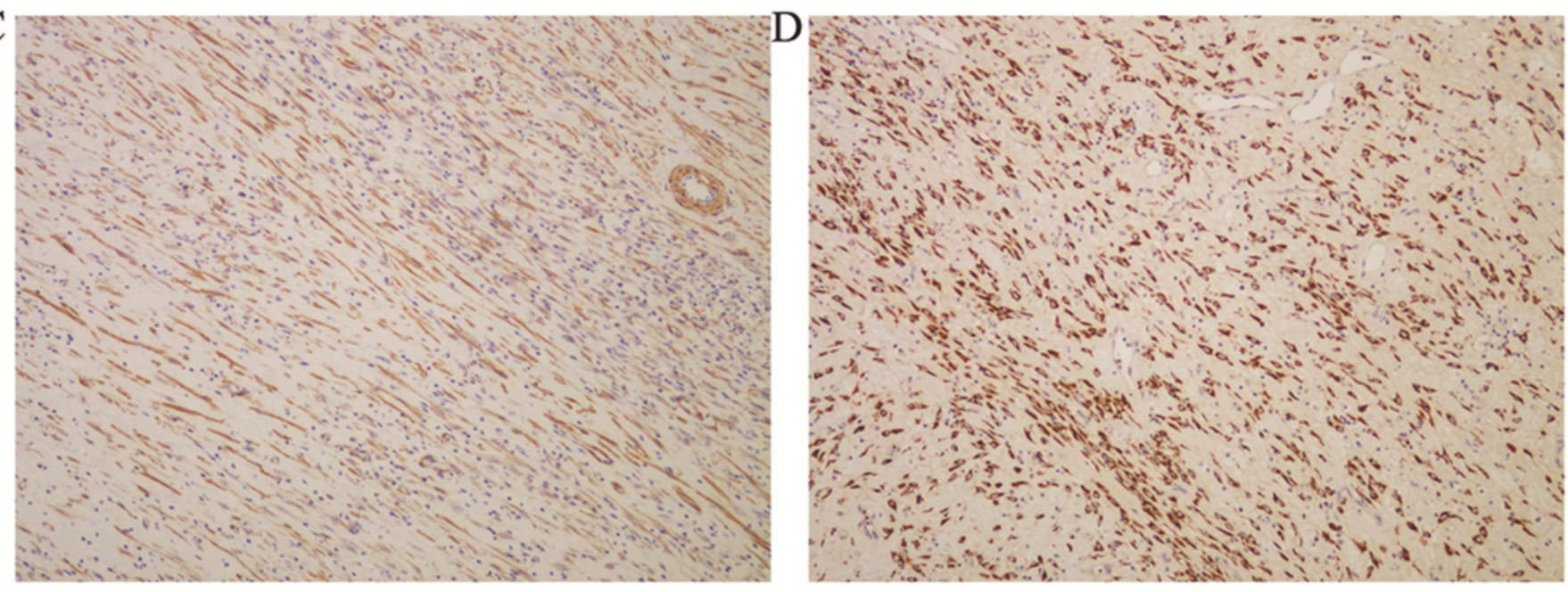

$\mathrm{E}$
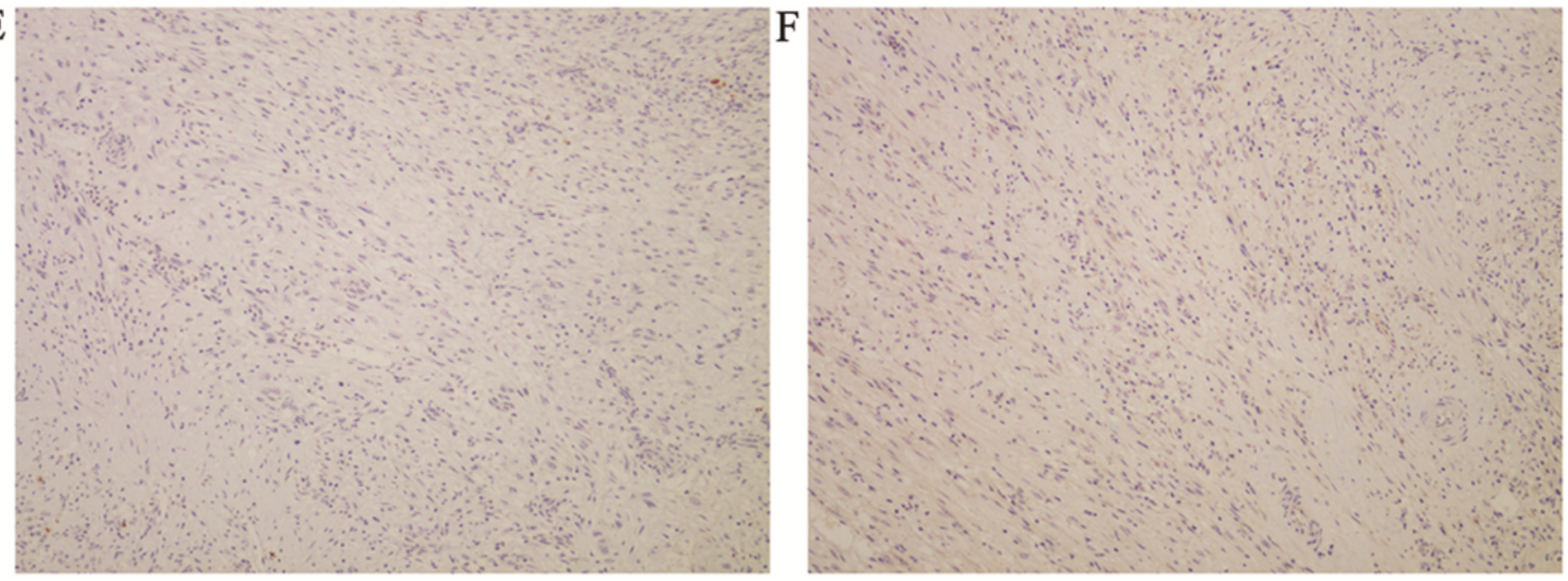

\section{Figure 4}

Inflammatory myofibroblastic tumor. Magnification, $100 \times$. Spindle and plump cells in diffuse inflammatory background; hematoxylin and eosin staining (A). Immunostaining of (B) desmin, (C) SMA, (D) ALK-1, (E) CD23, (F) S-100.

\section{Supplementary Files}


This is a list of supplementary files associated with this preprint. Click to download.

- CAREchecklistEnglish20131.pdf 